\title{
"LABIOS MÍOS TEMBLANDO, DEL PRECIOSO REGALO DE TU MANO, TIÑÉNDOSE": LA HUELLA DE PABLO GARCÍA BAENA EN EL DEVOCIONARIO DE ANA ROSSETTI ${ }^{1}$
}

\author{
"LABIOS MÍOS TEMBLANDO, DEL PRECIOSO REGALO DE TU MANO, \\ TIÑÉNDOSE": THE TRACE OF PABLO GARCÍA BAENA \\ IN ANA ROSSETTI'S DEVOCIONARIO
}

\author{
Carmen MEDINA PUERTA \\ Universitat de Lleida \\ carmen.medina@udl.cat
}

\begin{abstract}
Resumen: Este ensayo pretende evidenciar el magisterio que Pablo García Baena (Córdoba, 1921-2018), miembro fundador del grupo Cántico de Córdoba, ejerció en la obra poética de Ana Rossetti (San Fernando, 1950), particularmente en su poemario Devocionario (1986). Con este fin se lleva a cabo un análisis minucioso de la obra lírica de ambos que demuestra el gran número de rasgos estéticos que comparten, entre los que sobresalen: el uso de un lenguaje estetizante - rico en matices y detalles preciosistas-, la exaltación de los sentidos y, principalmente, el empleo del imaginario católico al que los dos recurren con un propósito, más que religioso, decorativo. En última instancia, este estudio comparativo trata de iluminar algunas de las claves de Devocionario que la crítica, debido a una falta de comprensión, ha tendido a malinterpretar. Concretamente, se ha sobredimensionado el componente erótico del libro de la gaditana.
\end{abstract}

Palabras clave: Pablo García Baena. Ana Rossetti. Devocionario. Poesía española del siglo XX.

Abstract: This essay will address the influence of Pablo García Baena (Córdoba, 19212018), a founding member of the literary group Cántico (Córdoba), in the poetry of Ana Rossetti (San Fernando, 1950), particularly her book Devocionario (1986). To achieve this, attention is paid to the poetic work of both writers, showing common aspects in their aesthetics, such as the outstanding use of language — rich in nuances and details - , the exaltation of the senses, and, mostly, the use of Catholic imagery, to which both resort with a decorative rather than a religious purpose. This comparative study will also approach some of the keys of Devocionario, which has been misunderstood by the critics. Particularly, scholars have exaggerated the erotic component of this book.

\footnotetext{
1 Esta investigación ha sido posible gracias al apoyo del Ministerio de Economía, Industria y Competitividad de España, mediante la formalización de un contrato predoctoral (FD) con referencia BES2016-079004. Asimismo, este trabajo forma parte del proyecto de investigación "La literatura de la transición democrática española y las narrativas transicionales europeas" (PID2019-107821GB-I00).
} 
Keywords: Pablo García Baena. Ana Rossetti. Devocionario. Twentieth-Century Spanish poetry.

\section{INTRODUCCIÓN}

Cualquier lector que se haya acercado a la obra poética de estos dos escritores andaluces se habrá percatado fácilmente de que sus personalísimos estilos se hermanan y de que ambos comparten todo un arsenal de referencias literarias: desde la Biblia hasta Góngora, pasando por San Juan de la Cruz. Si bien dicha relación literaria salta a la vista hasta el momento no ha recibido la atención crítica que merece. A excepción de estas páginas, no se ha escrito ningún otro ensayo académico que estudie con exhaustividad este parentesco, a pesar de que es a todas luces manifiesto. Lo cual no deja de sorprendernos ya que ambos gozan de un notable reconocimiento crítico e institucional. Con todo, Florencio Martínez Ruiz (1987: 48), Manuel Vilas (1995: 5), Juana Castro (2010: 230) y Amelina Correa Ramón (2019: 13) han señalado someramente en sus respectivas aportaciones que la estética del grupo Cántico dejó una profunda huella en los primeros libros de poesía de Ana Rossetti, principalmente en Devocionario (1986). Basta citar las palabras de profesora Amelina Correa Ramón (2019: 13) para ilustrarlo:

Sin duda, Rossetti comparte también rasgos que son imprescindibles ingredientes de su poética primera con el Grupo Cántico, de Córdoba, como su barroquismo, su lenguaje suntuoso y una concepción entre voluptuosa y muy sensorial de los ritos, imaginería y liturgias vinculadas con el catolicismo, surgida de la poderosa raigambre de lo que se ha vivenciado íntimamente desde la infancia, partiendo de una singular concepción de la belleza, experimentada con gozo y sin culpa.

En este sentido, aquello que tratamos de evidenciar en nuestras páginas es que ambos se sirven de un "culturalismo religioso", marbete que Guillermo Carnero (2009: 68) empleó para definir uno de los rasgos más sobresalientes de la estética del poeta cordobés, con la finalidad de recrear situaciones y temáticas profanas ligadas principalmente a los recuerdos y vivencias de sus respectivas infancias, las cuales transcurrieron en el mismo espacio geográfico e idéntica atmósfera cultural: la Andalucía de provincias. El hecho azaroso de que ambos vieran la luz y se desarrollaran en tierras andaluzas ha marcado profundamente sus respectivas cosmovisiones y sus obras literarias. La convivencia con la liturgia, el fervor que despierta la Semana Santa, la explosión floral que se produce en primavera y los olorosos efluvios que se respiran en las calles las noches de verano han configurado su forma de entender el mundo y son el marco sobre el cual cifran sus preocupaciones estéticas (Espada Sánchez, 1989: 477; Colinas, 2009: 20; García Galán, 2003: 142-143; Robbins, 2004: 35). Tal como han atestiguado, respectivamente, ambos poetas. Pablo García Baena lo exponía del siguiente modo en los actos celebrados en Bujalance en 1985: 
Mucho se ha hablado y dudado de la religiosidad de los poetas de Cántico, pero tan sincera era la exaltación carnal como el cordonazo penitencial que desemboca en un Miércoles de Ceniza. De esa paganía, que era solo un total rendimiento a la belleza, de esa liturgia ornamental y andaluza tan grata a los sentidos y a Dios, se nutrió Cántico (en Carnero, 2009: 121).

Por su parte, Ana Rossetti también ha indicado en diversas ocasiones que en la Andalucía de su niñez estaba muy presente la religión católica (en Fernández Rubio, 1987: 33; en Ugalde, 1991: 154-155). Por este motivo, estos códigos han dejado una fuerte impronta en su poesía, particularmente en Devocionario:

El hecho de que aproveche el catolicismo viene de que mi formación es católica, y me parece una cultura interesante que creo absurdo rechazar [...] Mi herencia es cristiana, y la aprovecho [...] Cuando era pequeña y asistía a estas celebraciones en latín no podía mantenerme ajena. Los sacerdotes, el incienso, los manteles de tul con lentejuelas, los diáconos y los acólitos, todo era una expresión muy fuerte, que he intentado recrear (en Fernández Rubio, 1985: web).

De hecho, Ana Rossetti en la entrevista que mantuvo con Emilio Coco (1986: 61) remarcó que durante su infancia la Iglesia católica ocupaba un lugar privilegiado en la vida social de provincias ya que no solo ejercía de punto de encuentro, sino también de foco cultural. Especialmente en una región como Andalucía, donde las tradiciones y ritos católicos tienen un profundo calado (Robbins, 2004: 34). Sin embargo, Ana Rossetti ha precisado que en su caso la cultura católica no fue exclusivamente una imposición externa, sino que, en muchas ocasiones, accedió a ella de motu proprio: "Yo no puedo dejar atrás esa educación religiosa, sobre todo porque fue por mí una cosa consentida" (en Coco, 1986: 51). En esta línea, la escritora ha puntualizado que, además de la educación católica obligatoria, recibió una formación litúrgica durante el ejercicio del oficio de sacristana que realizó de manera voluntaria (en Coco, 1986: 61-62). Asimismo, ha reconocido que de niña la lectura de las hagiografías, fascinantes y turbadoras para una mente infantil, solía ocupar sus tardes y que incluso sus padres llegaron a prohibírselas porque el contenido era tan cruento que no les parecía adecuado para su edad (en Coco, 1986: 58; en Ugalde, 1991: 151-152). Anécdota que rememora en el poema "Martyrum Omnium" (2004: 142): "Queridos compañeros de la infancia, / lecturas prohibidísimas, [...] / En mi regazo todos, puntual asistía / a la cruel peripecia del martirio. / Seductoras palabras: garfios, escorpiones, / erizados flagelos, pez hirviente... / mi cabeza inclinada en ellas zambullía / su turbio sobresalto". En definitiva, es fundamental manejar toda esta información de carácter biográfico dado que el legado cultural del catolicismo, omnipresente en la sociedad española del franquismo, marcó de manera clara buena parte de su producción literaria. Particularmente Devocionario (1986), en el cual reconstruye la educación religiosa y litúrgica que recibió durante su infancia. Es fundamental subrayar que las coordenadas sociohistóricas, es decir, el nacional catolicismo reinante (Gracia 
García y Ruiz Carnicer, 2001: 39-40), también explican el hecho de que ambos poetas utilicen de manera frecuente en su discurso lírico términos que proceden de la liturgia católica. Basta leer títulos como "El Corpus" (Antiguo muchacho [1950]) y "Viernes santo" (Antes que el tiempo acabe [1978]) de Pablo García Baena, así como "El gladiolo de mi primera comunión se vuelve púrpura" (Los devaneos de Erato [1980]), "Festividad del dulcísimo nombre" y "Exaltación de la preciosa sangre" (Devocionario [1986]) de Ana Rossetti para comprobarlo. No obstante, es imprescindible tener presente que ninguno de ellos hace poesía religiosa, sino que ambos se sirven de este imaginario para desplegar sus reflexiones acerca de cuestiones como la pérdida de la inocencia infantil, el despertar sexual o la reacción contra unas convenciones sociales opresoras y asfixiantes (D’Ors en García Martín, 1996: 20). Además, es esencial entender que la apropiación que hacen ambos de la religión católica no es, en sentido estricto, ortodoxa, sino que combinan muchos de sus símbolos con elementos paganos de la cultura greco-romana (Robbins, 2004: 32$)^{2}$. De hecho, ambos han asumido abiertamente este sincretismo (Rossetti en Cobos, 1994: 222-223, 227-228). Especialmente ilustrativas resultan las siguientes declaraciones del poeta cordobés: "lo cristiano, lo pagano... Para mí nunca fue un combate entre una cosa y otra. Era simplemente asumir el legado del que nacimos [...] Yo no veo en eso ningún conflicto" (en García, 2008: 27).

En definitiva, en las sucesivas páginas se tratará de demostrar que cuando Rossetti se sirve del imaginario católico en Devocionario (1986), por ejemplo, cuando reescribe la vida de los mártires, como veremos con el caso de Santa Inés ("Santa Inés en agonía"), está haciendo lo mismo que hizo en su día García Baena en un poema como "Himno a los santos niños Acisclo y Victoria" de Antiguo muchacho (1950). Es decir, desplegar sobre la parafernalia católica una reflexión que, a la postre, más que clerical es "arreligiosa" (Colinas, 2009: 21; Carnero, 2009: 71).

\section{HUELLAS BAENIANAS EN DEVOCIONARIO}

Devocionario se publicó en la editorial Visor de poesía en 1986 tras haber sido galardonado en la tercera edición del ya desaparecido premio Rey Juan Carlos de Poesía que otorgaba el ayuntamiento de Marbella. Este libro despertó un gran interés entre la crítica, tal como demuestran las numerosas y elogiosas reseñas que recibió (Giménez Frontín, 1987: 41; Martínez Ruiz, 1987: 47; García Martín, 1997: 19), y no ha dejado de captar la atención dentro y fuera de nuestras fronteras. No obstante, la autora ha declarado abiertamente sentirse arrepentida de haber escrito esta obra (en Patrón Sánchez, 2018: web). Confesión que no deja de sorprendernos porque Devocionario es, sin duda, una obra maestra. La frustración que le produce el haber escrito Devocionario se debe a que

\footnotetext{
${ }^{2}$ El tema del sincretismo y del clasicismo en la obra de ambos autores ha merecido diversos estudios críticos. Para una lectura atenta de esta cuestión, véase a propósito de la obra de Ana Rossetti, Luján Martínez (1997), Sánchez Dueñas (2001) y Merino Madrid (2015). Y para una lectura en clave clásica de la obra de Pablo García Baena, consúltese González Iglesias (2010).
} 
a lo largo de los años ha comprobado que, de manera recurrente, la crítica ha errado en sus interpretaciones sobre el contenido de la obra. Lo cual achaca a que ella se equivocó en la forma que eligió para lo que quería transmitir: los recuerdos de su infancia y el primer contacto que tuvo con el lenguaje literario a través de los misales y los devocionarios católicos. En palabras de la autora:

Muy poca gente ha entendido [Devocionario] como a mí me gustaría que se entendiese. Quizás sea una tontería, pero es que lo veo como un libro frustrado, aunque la gente pueda sacar algo de él, leer lo que le dé la gana... Sin embargo, no han dado con el tono que yo pretendía transmitir, y, por ello, me doy cuenta de que no lo debería haber escrito así. Hubiera quitado unos cuantos poemas que, quizá, despistan un poco [...] No puedo evitar tener la sensación de que, si yo fuese una poetisa del Siglo de Oro y la gente se interesase por estos poemas, investigaría. Se metería en la hagiografía, en la liturgia... Intentaría recuperar ciertas claves. En definitiva, lo desglosaría de otra forma. Pero se suele tratar como si fuese una revancha... No sé. Me llegaron a decir que el libro destilaba ira y rencor [...] Lo que me parece raro es que todo el mundo admite que no sabe nada, no digo ya de hagiografía o liturgia, sino del catecismo, pero luego se lanzan a interpretar sin mirar siquiera el misal romano. Los títulos dan pistas, pero si no se sabe a qué se refiere el título mismo, poco podemos hacer [...] La cuestión es que no se entendió nada, así que la conclusión que saco es que yo me equivoqué en la forma de expresarlo (en Patrón Sánchez, 2018: web).

En este sentido, una de las hipótesis que tratamos de demostrar en este ensayo es que en Devocionario Ana Rossetti ni subvierte, ni trasgrede, ni parodia, ni reacciona contra los dogmas católicos, como buena parte de la crítica ha sostenido (Wilcox, 1989: 336337; Ugalde, 1990: 27; Escaja, 2004: 121 y 2013: 210; Sherno, 1995: 298; Llorente Torres, 2000; Rosal, 2006: 28-29; Rosas, 2012: 154-155), sino que utiliza estas claves para tratar episodios y recuerdos autobiográficos. A partir del imaginario católico y del lenguaje litúrgico la autora recrea sus propias vivencias ya que, como se ha referido previamente, su forma de entender el mundo está indisolublemente ligada a la cultura católica en la que tanto ella como el resto de niños de su generación se formó (García Martín, 1997: 19; Céspedes, 1997: 6-7). No obstante, el excesivo carácter erótico que se le ha otorgado a Devocionario además de los prejuicios que pesan sobre el acervo cultural católico, por otra parte, inseparable de la cultura española, han sido perjudiciales para las lecturas posteriores. Entendemos que estos prejuicios se deben, en gran medida, al hecho de que su poemario Los devaneos de Erato (1980) fuera un libro de temática erótica y también de que a posteriori ganara el premio de narrativa "La Sonrisa Vertical" por su colección de cuentos Alevosías (1991), como apunta Alejandro Céspedes (1997: 6) en el prólogo a la reedición que Plaza y Janés hizo de Devocionario.

Además, a nuestro juicio, la insistencia de la crítica en otorgar a Devocionario una lectura anticlerical viene dada del planteamiento maniqueo consistente en contraponer de manera antagónica la liberación sexual que se produjo en España a finales de los años setenta frente a la moral católica impuesta durante el franquismo, como si la Transición hubiera sido un corte limpio en la Historia. De manera general, se ha tendido a asumir 
que todo aquello que tuviera que ver con la religión católica, tan presente en la cultura de nuestro país mucho antes de la dictadura de Franco (Robbins, 2004: 33), era obligatoriamente de corte reaccionario y que toda apropiación de alguno de sus aspectos no podía ser sino subversiva. Máxime cuando, como ocurre en el caso de Rossetti, tal apropiación la realizaba una pluma femenina, como pone de manifiesto el análisis de Tina Escaja (2013: 189, 210):

Esta transferencia del deseo infructuoso de la palabra para los novísimos hacia la celebración de la lengua en Rossetti (en su sentido lingüístico y carnal), marca asimismo la transferencia entre una tradición principalmente heterocéntrica y patriarcal implícita en el canon literario y enfatizada en el discurso católico que revisa Rossetti en su Devocionario, hacia un discurso que exalta las diferencias dentro de un contexto sociohistórico de efervescencia postfranquista que se reconoce en la movida madrileña, en la que se sitúa y de la que participa la propia Rossetti [...] Como hemos visto, la detención en dos grupos de poemas del segmento "Devocionario" del libro homónimo de Ana Rossetti muestra la voluntad subversiva y celebratoria del poemario más acabado de la autora, en su lograda intersección de la erótica de la carne, con la erótica del lenguaje.

Sin embargo, Rossetti no pretendía subvertir la cultura católica con fines paródicos, sino, como venimos indicando, rememorar sus propias vivencias a partir de los códigos que marcaron su cosmovisión (Viejo, 2004: 15). Asimismo, la apropiación de la cultura católica con fines profanos no era un recurso inédito hasta la irrupción de la gaditana en el panorama literario, sino que contaba con el precedente de la estética del grupo Cántico de Córdoba. De hecho, Guillermo Carnero (2009: 97) puso de realce que entre los rasgos más llamativos de la estética Cántico y, por extensión, de Pablo García Baena, sobresale: "el entender la religiosidad como un espectáculo y como un universo de exquisitez y de analogía con la experiencia vital propia, algo que no excluye la creencia misma, pero la desplaza a un terreno secundario". En este sentido, la gaditana comparte con el cordobés la utilización del imaginario bíblico y hagiográfico para desplegar sus reflexiones acerca de asuntos como la pérdida de la inocencia infantil o el despertar sexual. Por ello, no es baladí que en Devocionario la gaditana dedique el poema "La anunciación del ángel" a Pablo García Baena y encabece "Llámame" con una cita de Julio Aumente, como señalaron muy oportunamente Víctor García de la Concha (1995: 22) y Amelina Correa Ramón (2019: 14), sino que, a nuestro juicio, es una forma de tender puentes hacia el precedente grupo Cántico con el que buscaba emparentar su pensamiento poético. Con el fin de demostrar esta hipótesis, en las siguientes páginas desarrollamos un atento análisis de la obra poética de García Baena y Rossetti.

\section{1. Ángeles y demonios: símbolos del despertar sexual}

La clásica oposición que encarnan los ángeles y el demonio es utilizada por ambos poetas para materializar la reflexión sobre la pérdida de la inocencia, la toma de conciencia sobre los peligros que entraña la tentación, así como los primeros deseos 
carnales que aparecen en sus respectivas obras poéticas. En el caso de Pablo García Baena, el poema que mejor ilustra el despertar sexual y la primera toma de conciencia de la tentación carnal es "Tentación en el aire" de Rumor oculto (1946). Guillermo Carnero (2009: 65-66; 2018: 24) ha interpretado que, en este poema, cifrado en el imaginario católico, la voz lírica expresa la tentación carnal que despierta la belleza y la voluptuosidad en el contexto del tórrido verano. Es por ello por lo que presagia el abandono de su castidad juvenil. Esta tentación incorpórea, producto de la propia vitalidad juvenil y de los efluvios que arrastra consigo la brisa veraniega, es encarnada en el poema por el ángel maligno, es decir, Lucifer, a quien la voz lírica se dirige. Asimismo, este poema ejemplifica a la perfección el sincretismo cultural que caracteriza los primeros libros de García Baena puesto que en él aparecen las figuras de Venus, Cupido y Apolo (versos 38, 39 y 50) junto a la de Jesucristo (versos 28, 71 y 72). También conviene indicar que, como señaló Luis Antonio de Villena (2018: 14), no es casual que para el grupo Cántico la figura del ángel sea un símbolo básico y fundacional, como evidencian las diferentes portadas de la revista, ya que más allá de su significación religiosa, esta figura encarna la perfección y la belleza juvenil y ambigua, así como la caída en el pecado. En esta línea, Teresa García Galán (2003: 220) ha indicado que la presencia de la figura del ángel en el discurso lírico de Pablo García Baena no ha de entenderse exclusivamente como un símbolo religioso porque, en muchas ocasiones, encarna al ser amado divinizado, como se advierte en "Tentación en el aire". Algo que también ocurre de manera evidente en el poema "La anunciación del ángel” que Rossetti dedica a García Baena y en el que el término ángel se emplea para hacer referencia a un cargador del paso de una procesión (Rossetti en Coco, 1986: 52). Para ilustrar todo lo apuntado sobre la poética baeniana, cabe que leamos el siguiente fragmento de "Tentación en el aire":

Sabía que vendrías a hablarme

y no te huía,

demonio, ángel mío, tentación en el aire.

[...] Antes de verte, lejos, te adiviné en mi alma,

como algún fauno joven que con su flauta báquica

avivara en mi carne

un fuego leve, quieto,

amenazado casi de apagarse algún día, rodeado de hielos, engaños de mí mismo.

[...] En silencio, callado, yo te entregué mi alma, aquella que había sido espada victoriosa, que había decapitado todas las tentaciones a ti, mi ángel malo, te la entregué sin lucha, y tú con tu sonrisa, ¡oh tu risa que hiere!, arrancaste de mí los altivos laureles y casi sin mirarlos, despreciaste a aquel que alargando la mano te los daba vencidos.

Por seguir tus caminos

dejé a un lado a Cristo,

tentación en el aire, ángel mío, demonio; 
deserté de las blancas banderas del ensueño para seguir, descalzo, tus huellas que manchaban.

[...] Aunque me hayas quitado a Cristo, el que perdona,

el comprensivo, el dulce, el manso Jesucristo, un día volveré al alba, ya cansado, con mis descalzos pies sangrantes de la senda y lloraré las lágrimas, las que tú no ves nunca, hasta llorar el último recuerdo del pecado (García Baena, 2018: 64-66).

La presencia de ángeles, así como de los demonios para tratar un tema como el despertar sexual es también una constante en Devocionario, principalmente en la sección "In conspectu angelorum". No podemos dejar de señalar que tanto los ángeles como los demonios también son presencias muy recurrentes en la obra narrativa de Rossetti, especialmente en los cuentos "Del prestigio del demonio" y "Et ne nos inducas" de Alevosías. Es fundamental indicar que estas figuras encarnan la dualidad, cifrada en clave erótica, de la pureza frente al pecado. Es decir, las figuras angélicas en la literatura de Rossetti son, por lo general, de una belleza asexuada, beatífica, mientras que la figura del demonio es la representación de la virilidad y, por ende, de la tentación carnal. En palabras de la autora: "Alguna parte de Devocionario, sobre todo la que está dedicada a los ángeles, está en la onda de Emilio Freixas [...] Los ángeles eran como hadas y los demonios hombres con unas ropas tan ajustadas que era igual que si estuviesen desnudos" (en Ugalde, 1991: 158). Es preciso indicar muy brevemente que Emilio Freixas (Barcelona, 1899-1976) fue un dibujante, considerado como uno de los ilustradores pioneros de historietas en España. Los cuadernillos de dibujo, así como los cuentos ilustrados por él gozaron de una enorme difusión durante los años sesenta, y dentro de su extensa obra es interesante remitir a títulos tan elocuentes como La vida de la virgen contada a los niños (1961), El ángel de la guarda (1961), Leyendas de Navidad (1961) y La pasión de nuestro Señor contada a los niños (1961), todos ellos editados en la editorial E. Meseguer de Barcelona. Este apunte tiene la pretensión de manifestar que las doctrinas católicas invadían todas las esferas de la España del franquismo, desde la educación hasta los productos de ocio que consumían todos los públicos, incluidos cómics y películas infantiles (Gracia García y Ruiz Carnicer, 2001: 116). A este respecto, es interesante remitir a un fragmento de una entrevista que mantuvo con Emilio Coco en la que la autora rememora las enseñanzas a propósito de las figuras antagonistas de los ángeles y los demonios que se difundían en su colegio, Compañía de María de San Fernando:

Para mí el demonio era el único hombre sobre la tierra, porque todo lo demás era más ambiguo. La figura del demonio era una figura viril. Yo sabía, y además nos lo recalcaban mucho las monjas, que se llamaba Lucifer, que quería decir Luzbel, luz de Dios y que era el ángel más bello de todos. Y que su rebelión fue porque se miró en un espejo y cuando tuvo consciencia de sí, dijo: ¡No sirvo! A mí eso me causaba mucha inquietud y mucha atracción y mucha morbosidad [...] Los ángeles eran para mí unas cosas muy atractivas, pero también muy familiares, no me daban ese miedo. Eran más femeninos, yo los comparaba conmigo, porque para mí no eran diferentes, eran una prolongación de mi colegio. Los ángeles eran como princesas, eran como elementos de mi casa, yo no los 
envidiaba ni nada. Simplemente los quería, porque eran como compañeros míos (en Coco, 1986: 59-60).

Sin duda, el texto que mejor ejemplifica el antagonismo descrito por la autora es "Del prestigio del demonio". En esta composición la voz lírica nos traslada al aula de un colegio religioso femenino de la España de mediados del siglo pasado y recrea cómo, durante las lecciones de religión, las niñas en su infantil candidez se sobresaltan al ser instruidas en los peligros de una figura tan tentadora como el demonio, desconocida para ellas hasta ese momento. Aquello que resulta más interesante de la composición es cómo Rossetti describe la emoción que les suscita la contemplación de su representación como una figura varonil perniciosamente atractiva cuando aún no son capaces de discernir con claridad los primeros indicios de sexualidad. Asimismo, para subrayar el carácter erótico que posee tal personalidad, Rossetti la contrasta con las familiares y afeminadas figuradas de los ángeles celestiales que las párvulas colegialas están acostumbradas a ver. A continuación, remitimos a un fragmento de este poema:

En los castos harenes celestiales ángeles epicenos con gestos de princesas de abigarradas túnicas, negligentes, las ropas arrastraban.

Abundantes los bucles sobresaliendo jónicos de graciosos tocados e iridiscentes las isósceles alas, biseladas y puras como piedras preciosas.

Palacio familiar, tal consonancia con las asiduas aulas femeninas - etéreo gineceo del conventoque ni el más alto arcángel nos despertó jamás envidia o sobresalto.

[...] Pero, a vuelta de página, ÉL se erguía, su capa henchida - del águila era vuelola firmeza viril de su torso arrogante circundaba. Membrana endeble y tensa auguraban sus ropas la dura vecindad de su cuerpo perfecto, y, turbador, el pie - peligrosa hendidura - insistentes acosos prometía.

Atrayente y temible sin duda era el demonio, del masculino enigma, único vaticinio. Y reverentemente los lápices guardábamos. La carne estremecida: crispación dolorosa de insoportable ansia en la cintura ardiéndonos (Rossetti, 2004: 160-161). 


\subsection{Hagiografía católica y figuras bíblicas}

La recreación de la vida de los mártires y los santos católicos también es una constante en la obra de ambos poetas andaluces (Martínez Ruiz, 1987: 48; Colinas, 2009: 20). En el caso de Devocionario destaca la notoria presencia de la hagiografía: Santa Bárbara, Santa Inés, San Lorenzo, San Esteban, Santo Tomé y Santa Elena (Escaja, 2004: 123). Sin olvidar que en su ópera prima, Los devaneos de Erato, Rossetti consagró un texto al martirio de San Sebastián (“A Sebastián, virgen"). Por su parte, Pablo García Baena dedica diferentes poemas a estas figuras, entre otras cabe señalar "Himno a los santos niños Acisclo y Victoria" (Antiguo muchacho [1950]) y "Cántico de los santos a nuestra señora" (Óleo [1978]). Para ilustrarlo cabe que nos detengamos en "Himno a los santos niños Acisclo y Victoria" de Antiguo muchacho (1950). Este poema está dedicado a los patronos de Córdoba, dos hermanos mártires paleocristianos que murieron bajo la persecución de Diocleciano (304 d. C.), cuya festividad se celebra el 17 de noviembre. Citamos a continuación un fragmento:

[...] Porque ahora mi alma se me deshace en polvo

de lejanos caminos, quiero cantar sin tregua a vosotros, los puros, a vosotros, los santos, hasta que mi voz sea como flor de granado enrojecida por la sangre de mi garganta, a vosotros, los justos, a vosotros, oh niños.

[...] Estréchame en tus brazos helados como sombras, fría noche de Noviembre, y que de tu regazo gotee la caricia suave de la lluvia, de la lluvia que oculte a mis ojos el cuerpo de Victoria en el anfiteatro, allí donde los mármoles son blancos como un deseo insatisfecho.

Aparta de mí, oh noche, la sangre que resbala hasta teñir el río de su cárdeno grito, la sangre que derrama la cabeza cortada por un sueño de espanto, de Acisclo, puro y limpio como un ángel ahogado en el fondo de un pozo.

Aparta de mí, noche más piadosa que el alba, los destrozados cuerpos de estos niños, de estos niños que apenas unos días jugaban en las fuentes cercanas a su casa o escribían sus nombres en la cal palpitante de las blancas paredes, cuando en la siesta cálida la calle se adormece en el aire parado (García Baena, 2018: 121-122). 
El sentido de esta alabanza es reflexionar sobre cómo la muerte prematura procura que el mundo de la infancia permanezca incorrupto (Villena, 2010: 144-145). A este respecto, Carnero (2009: 71; 2018: 54) subraya que el episodio religioso es, en realidad, un pretexto, un marco sobre el cual proyectar las preocupaciones del poeta. Algo que también evidencia "Llanto de la hija de Jephté" (Mientras cantan los pájaros [1948]) donde el poeta cordobés trata de nuevo el tema de la virtud como consecuencia de la expiración prematura. La trágica historia del caudillo hebreo Jephté, que pertenece al Libro de los Jueces $(11,29-40)$ del Antiguo Testamento, se resume en que Jepthé le prometió a Yahvé que si le concedía la victoria sobre los ammonitas como ofrenda le sacrificaría el primer ser vivo que le saliera al encuentro al regresar de la guerra. La tragedia fue que la primera persona que recibió a Jepthé fue su hija, Gidá. Gidá aceptó sin vacilaciones su funesto destino, pero a cambio pidió a su padre que antes de que se consumase su ejecución le dejara llorar por su virginidad durante dos meses (Carnero, 2018: 40). Citamos a continuación un fragmento del poema:

[...] Porque mi padre hizo un voto al Señor y yo he de cumplir su palabra. Y mi vida será ya como un río entre muros que tiene marcada la ruta y nada le puede hacer que varíe su cauce [...] Un río donde se tienden las redes ambiciosamente para sacar la pesca y sólo el agua escapa por las cuerdas entretejidas, las redes volverán al fondo de la barca avergonzadas como un vientre estéril. [...] y tú alma mía, cuéntate una vez más lo sucedido aquella noche ahora que las palomas se paran sobre mis hombros desnudos, sobre mis brazos desnudos y picotean en la manzana virgen de mi pecho que yo resguardo con la inocencia cruzada de mis brazos, igual que la campesina cubre con un lienzo la bandeja donde incitan granadas y membrillos.

[...] ¡Oh doncellas, llorad conmigo mi virginidad por los montes! Cubrid vuestros cuerpos con los más rudos paños, vuestros pies de la más basta sandalia, para que yo no recuerde en vuestras groseras cinturas la cintura viva de los jóvenes, en vuestro torpe andar sus gráciles pasos en el baile.

[...] Venid, que quiero olvidar la magnolia selvática de mi cuerpo apenas entreabierta en la mañana.

Quiero liberarme de la sofocante red de los deseos.

Apagar toda lumbre, como el centinela apaga en el arroyo su antorcha escarlata cuando la aurora despliega el livor de su clámide entre los árboles más lejanos.

[...] Guiadme en mi ceguera hasta la muerte antes que el día escape como un pájaro ígneo.

Guiadme, que presiento su augusto poderío rozando por mi carne.

Soltad mi cabellera de sus cintas.

Desceñid mis sandalias.

Rasgad mis vestiduras que quiero ir a sus brazos desnuda como un templo al son de los adufes.

¡Oh virgen que sonríes entre los duros pliegues de tu manto, amante del silencio y la quietud, dame tu calma! (García Baena, 2018: 87-93). 
Según Guillermo Carnero (2009: 67) y Teresa García Galán (2003: 165-166), García Baena se sirve de la historia de Gidá, esta figura femenina que acepta ser sacrificada en nombre de las convenciones sociales, para codificar un alegato contra las normas y las leyes que, por medio de la fuerza y la coacción moral, reprimen la vivencia de la sexualidad libremente. Por su parte, Villena (2007:14) señala que el cordobés recurre a la ambigüedad entre lo sacro y lo profano para tratar un tema como la homosexualidad masculina que, si bien cuenta con una larga tradición en la literatura, era tabú en la España franquista. Además, Carnero (2018: 26-27) indica que García Baena se sirve de personajes femeninos, como ocurre en "Verónica" de Mientras cantan los pájaros (1948), para cifrar sobre una escena religiosa una reflexión sobre el amor y la sexualidad que queda en sombras con el objetivo de elaborar un objeto artístico cuya inspiración se basa en una experiencia personal de la cual se desea distanciar. Estrategia que ha sido definida por Luis Antonio de Villena como "teatro de mujeres" (2018: 17).

Por su parte, Ana Rossetti también recurre a la presencia de mártires en Devocionario con un fin denunciatorio. Un claro ejemplo de ello lo constituye la composición "Santa Inés en agonía". Según el Año cristiano (Croisset, 1894: 352-359), la mártir paleocristiana conocida como Santa Inés vivió en Roma durante el siglo III d. C, momento en que el Imperio romano estaba bajo el poder del emperador Diocleciano. Era hija de una familia noble y rica y fue educada en el cristianismo. Siendo aún una niña resolvió consagrar su vida a Jesucristo. Es decir, no tomar esposo. No obstante, su belleza era tal que atraía la atención de los jóvenes. Cuando Inés contaba con solo trece años, fue pedida en matrimonio por Procopio, hijo de Sinfronio, el gobernador de Roma. Inflamado de amor por la joven, Procopio reiteró su oferta en numerosas ocasiones que Inés rechazó sucesivamente debido a su firme convencimiento: “Apártate de mí, aguijón del pecado, tentador importuno, y ministro del padre de las tinieblas. No te canses en aspirar a la mano de una doncella que ya está prometida a un Esposo inmortal, único dueño del universo, y que solo dispensa a sus favores a las vírgenes puras y castas" (Croisset, 1894: 353). Ante la reiterada negativa, Sinfronio mandó llamar a la joven para convencerla de que aceptase la propuesta de su hijo, Procopio. Sin embargo, la joven se mantuvo fiel a su fe. Para castigarla por haber hecho voto de castidad el gobernador la mandó encerrar en un prostíbulo para que allí fuese ultrajada. Pese a ello y gracias a la intermediación de su ángel de la guarda pudo preservar su virginidad. Milagrosamente, el ángel convirtió el lupanar en un oratorio. Ante los prodigios que obraba la casta Inés, los sacerdotes la tomaron por bruja y pidieron al regidor que mandase quemarla en la hoguera. No obstante, una vez en la hoguera, la mediación de Jesucristo hizo que las llamas se apartaran del débil cuerpo de Inés. El pueblo asombrado ante tales sucesos la tomaron por hechicera y pidió al gobernador que la condenara a muerte. Finalmente, Inés decidida a unirse para siempre a Jesucristo suplicó a su salvador que no intercediera por ella y expiró degollada, lo cual le permitió entrar en los cielos recibiendo la doble corona del martirio: la de mártir y la de virgen. En el lugar de su sacrificio, el emperador Constantino mandó construir una iglesia que lleva su nombre. Aunque se ha de tener en cuenta que el poema de Rossetti, 
más que reescribir la hagiografía en sentido estricto, la utiliza como un marco referencial sobre el cual cifra un suceso que tuvo lugar en Roma en el año 1982 cuando residía en la capital italiana. En palabras de la autora:

En este poema comparo el martirio de Santa Inés con un hecho que sucedió durante mi primera estancia en Roma en el mismo lugar donde Santa Inés fue martirizada; la piazza Navona, antes plaza de la Agonía, pues allí se libraban luchas de gladiadores. Donde está ahora la iglesia de Santa Inés in Agona existió un lupanar donde la santa, con la misma edad que la protagonista del poema, fue llevada para ser profanada. Dicen que la salvó un ángel. En el verano del 82, junto a esa iglesia raptaron a una chica, la violaron y estuvieron a punto de matarla. En el juicio se la intentó culpar a ella porque tenía la falda corta, el pelo suelto, porque no se defendió lo suficiente y en fin... Y mucha gente aunque la compadecía de algún modo estaba de acuerdo en que la chica andaba provocando. Desde luego no veo ningún erotismo en el hecho de que una chica violada de trece años, pida que se la proteja de todas esas acusaciones - ella no tuvo un ángel como Santa Inés- (en Crépiat y Lavergne, 2017: 460).

Sin más dilación, leamos el poema:

\section{Ne derelinquas me, ne discedas a me}

PS., 37

Sabes que son mis manos desvalidas y mansas, que tengo trece años y que este largo pelo, enredado vellón que mi párvulo pecho apenas se acuchilla, es un endeble escudo. Defiéndeme tú pues en la lisa acera rebotan de continuo brazadas de amapolas, y en mis ojos la inocencia asomada seduce demasiado, es valioso argumento para abrir charoladas portezuelas, alcanzarme, someterme al asedio, precipitarme al pavoroso túnel del total desamparo, para luego emerger de entre mis ropas rotas y esparcidas; los muslos empapados y en mi boca el viscoso sabor de la mayor vergüenza. Defiéndeme tú porque todo me culpa: el desvanecimiento, la poca ligereza de mis piernas, el cimbrear, incluso, que tienen mis vestidos, el tener trece años, el sedal de mi pelo, y que mis manos sean desvalidas y mansas (Rossetti, 2004: 150).

En primer lugar, es preciso advertir que el título, como se ha indicado, remite a la mártir católica Santa Inés, de manera que el poema establece un paralelismo a partir de la imagen del cabello entre la referencia sacra y la niña romana anónima que sufrió un asalto sexual. A ambas se las caracteriza con una larga melena que se esparce por sus respectivos 
pechos, pero, mientras que para la mártir este atributo tenía cualidades protectoras, como refleja la pintura "Santa Inés en la prisión" (1641) de José de Ribera, en el caso de la joven violentada, al carecer de un ángel que obrara milagros, la largura de su cabello no la mantiene alejada de miradas lascivas, sino que más bien las atrae hacia sí, tal como reflejan los siguientes versos: “[...] este largo pelo, / enredado vellón que en mi párvulo pecho / apenas se acuchilla, es un endeble escudo" y "porque todo me culpa: el desvanecimiento / [...] el sedal de mi pelo".

En relación a la intermediación del ángel custodio que refiere Rossetti, podemos observar cómo, aunque en el poema no se menciona directamente, la víctima se dirige a una instancia, que suponemos divina, implorando auxilio, tal como repiten los versos $5 \mathrm{y}$ 17: "Defiéndeme tú", mensaje que también aparece de manera explícita en la cita introductoria del poema: "Ne derelinquas me, ne discedas a me", cuya traducción en español es "No me dejes, no te apartes de mí" (Rossetti, 2004: 353). Pese a su plegaria, la joven de apenas trece años es raptada por el ocupante, u ocupantes, de un vehículo desde el que es vislumbrada para, a continuación, ser sometida a un acto de violencia sexual: "y en mis ojos la inocencia asomada / seduce demasiado, es valioso argumento / para abrir charoladas portezuelas, / alcanzarme, someterme al asedio". A todo ello cabe añadir que su debilidad física no la exime de ser culpada por el estupro: "precipitarme al pavoroso túnel / del total desamparo, para luego emerger / de entre mis ropas rotas y esparcidas; / los muslos empapados y en mi boca / el viscoso sabor de la mayor vergüenza. / Defiéndeme tú / porque todo me culpa". De este modo, el poema no se limita a actualizar la hagiografía, sino que la narración de este suceso adquiere un carácter de denuncia feminista de índole universal. De esta manera, el poema sitúa al lector frente al espejo de una realidad tan trágica y vigente como es la culpabilización de las mujeres que sufren vejaciones, como ha apuntado Martha Lafollette Miller (1995: 272). Aunque no ahondaremos en esta cuestión porque supone un desvío de nuestra argumentación, queremos advertir que la situación de indefensión jurídica de la víctima de abusos sexuales que se retrata este poema no constituye un caso aislado, sino que, tristemente, es una realidad que continúa siendo vigente y que está globalmente extendida. En este sentido, en diferentes ocasiones el mensaje original que quería transmitir la autora en esta composición ha sido malinterpretado ya que, en lugar de leerse el poema en términos de alegato contra la violencia sexual y de denuncia de la respectiva inculpación que sufren las víctimas, se le ha atribuido un carácter erótico que lo despolitiza de su sentido original. Como ejemplo cabe remitir a la interpretación que realizó María Inés Zaldívar (1998). Si bien es justo admitir que Zaldívar lleva a cabo un gran trabajo de documentación histórica (101-102, 109) y además es muy certera a la hora de interpretar algunos de los aspectos del poema: el carácter universal que la indefinición espacial y temporal otorga a la escena, la dualidad que encarna el sujeto lírico, que remite al mismo tiempo a la mártir cristiana y a la menor contemporánea (117-120), no obstante, la lectura que hace de este poema está cargada de clichés. Zaldívar incurre en el error de otorgar una interpretación venérea del texto que redunda en los clásicos prejuicios machistas al afirmar que la voz lírica del 
poema, más que ser víctima de un abuso, es la instigadora de tan truculento episodio, como evidencian las siguientes líneas: "De esta manera, lo que sucede en el interior del vehículo puede considerarse, tanto como un ultraje sexual, la innoble violación de una menor, como el cumplimiento de un deseo, o bien un perverso juego infantil buscado por la pequeña callejera" (1997: 115). Sin embargo, Zaldívar no es la única crítica que se excede a la hora de interpretar este poema en clave erótica. John Wilcox (1989: 337) afirma sin empacho que: "Santa Inés pide protección, porque a los trece años ya es una chica muy atractiva abusada por los hombres [...] Esta santa se presenta aquí como sexualmente precoz; es decir que el discurso descubre lo que la tradición patriarcal nunca ha visto, o que sencillamente ha suprimido". Mientras que Shirley Mangini (1996: 204) ha afirmado que el poema describe una escena de onanismo: "Santa Inés en agonía' revela la culpabilidad del deseo masturbatorio —el sujeto/objeto es una niña de trece años que pide ayuda en una pseudo-oración-_." El carácter superficial y tendencioso de este tipo de análisis ha sido perjudicial para la recepción Devocionario, como la propia autora advirtió:

Cuando estuve viviendo en Roma, raptaron a una niña de trece años en ese lugar y la violaron... Ella no tuvo un ángel. Ese es el poema. Pues me han llegado a decir que mi poema se trataba de una masturbación. Puedo entender que no todo se sepa, pero si lo lees y no lo comprendes, ¡investiga sobre santa Inés! Por eso digo que no se analizan a los contemporáneos con la minuciosidad que se les presta a los de siglos anteriores (en Patrón Sánchez, 2018: web).

\section{CONCLUSIONES}

En definitiva, ha quedado de manifiesto que Devocionario fue escrito a la luz de la poesía de Pablo García Baena y que este ejerce un notable magisterio sobre la gaditana. Ambos comparten el gusto por el empleo del imaginario católico en la construcción de su discurso lírico. A ello cabe añadir que los códigos culturales que se insertan en la poesía de ambos es producto del contexto histórico y también de haber visto la luz en el mismo espacio geográfico: Andalucía. No olvidemos que en la escritura de ambos reposa un importante poso vivencial. En este sentido, nuestro esfuerzo por tender un puente entre ambos autores tenía la pretensión de demostrar que la poética rossettiana no es un fenómeno aislado y rupturista, sino que es heredera de la obra del cordobés. Al mismo tiempo, esta revisión de Devocionario tenía el objetivo de depurarlo de una serie de prejuicios que la crítica ha proyectado sobre él. En otro orden de ideas, es preciso señalar que existen otras muchas cuestiones que hermanan las obras de estos poetas y que cabría estudiar con detenimiento. Entre ellas, la influencia que han recibido de la literatura mística, particularmente la huella de San Juan de la Cruz, que es uno de los máximos referentes para ambos. Sin olvidar el importantísimo influjo que ha ejercido Góngora en sus respectivos estilos. También merece un estudio comparativo la presencia de las artes plásticas, así como de la música en sendas trayectorias. Como ejemplo del reflejo de la 
melomanía de ambos autores en su obra lírica basta citar "Elegía a Chopin en un atardecer de octubre" (Rumor oculto) de García Baena y "Recordatorios" de Devocionario: "Sigo aún en la música, / sigo aún apoyada en el dulce declive / de tu hombro: viernes doce de octubre, / Concierto en Mi menor de Félix Mendelssohn. / La Inacabada, Schubert, dieciséis de noviembre. / Veinticinco de enero, Mozart...". Cerramos, sin embargo, este estudio con el convencimiento de que los puentes literarios que los unen han quedado firmemente cimentados y con la confianza de que en el futuro la crítica seguirá trazando nuevos y esclarecedores caminos de ida y vuelta entre ambos.

\section{REFERENCIAS BIBLIOGRÁFICAS}

CARnero, G. (2009). El grupo Cántico de Córdoba. Un episodio clave de la historia de la poesía española de posguerra. Madrid: Visor Libros.

(2018). Pablo García Baena. Un navio cargado de palomas y especias. Sevilla: Junta de Andalucía / Conserjería de Cultura.

Castro, J. (2010). "Pablo García Baena, o la mirada...". En Pablo García Baena: misterio y precisión. Actas del Congreso internacional celebrado en Córdoba del 18 al 20 de noviembre de 2009, C. Fernández Prieto (ed.), 222-231. Sevilla: Renacimiento.

CÉSPEDES, A. (1997). "Prólogo para nuevos lectores". En Devocionario, A. Rossetti, 58. Barcelona: Plaza y Janés.

Cobos, M. (1994). "La mitología en la obra poética de Ana Rossetti y Juan Cobos Wilkins (Conversaciones con los autores)". En Las formas del mito en las literaturas hispánicas del siglo XX, L. Gómez Canseco (ed.), 219-239. Huelva: Universidad de Huelva.

Coco, E. (1986). "La verdadera Ana Rossetti (entrevista con la autora de Devocionario)". Zarza Rosa 7, 49-73.

Colinas, A. (2009). "Pablo García Baena: Claves para una poética intensa". Siglo XXI, Literatura y Cultura españolas: Revista de la Cátedra Miguel Delibes 7, 13-26. Disponible en línea: https://uvadoc.uva.es/handle/10324/28314?localeattribute $=$ en $[06 / 01 / 2021]$.

Correa Ramón, A. (2019), "Invitatorio". En Los devaneos de Erato, A. Rossetti, 9-29. Madrid: Tigres de Papel.

Crépiat, C. y LAVERGNE, L. (2017). "Entrevista 'Figuras en la poesía erótica moderna y contemporánea"'. En Masques, corps, langues. Les figures dans la poésie érotique contemporaine, C. Crépiat et L. Lavergne (eds.), 459-466. Paris: Garnier.

Croisset, P. J. (1864). Año cristiano. Tomo I (enero), J. María Díaz Jiménez (trad.). París: Librería de Rosa y Bouret. 
ESCAJA, T. (2004). "Framing the prayer book language and AIDS in Devocionario". P/herversions: Critical Studies of Ana Rossetti, J. Robbins (ed.), 120-132. Lewisburg: Bucknell University Press.

(2013). "Ludismo y culto al miedo en el Devocionario de Ana Rossetti". En La poesía iba en serio. La escritura de Ana Rossetti, J. Jurado Morales (ed.), 189210. Madrid: Visor Libros.

EsPada SÁnChez, J., ed. (1989). Poetas del sur. Madrid: Espasa Calpe.

Fernández Rubio, A. (1985). "Ana Rossetti: 'Sólo puedo ser desobediente"”. El País, 16 de diciembre. Disponible en línea https://elpais.com/diario/1985/ 12/16/cultura/503535609_850215.html [06/01/2021] (1987). "Ana Rossetti: el mundo por montera". El País, 8 de marzo, 32-33.

GARCíA, E. (2008). “Travesía. Pablo García Baena (Entrevista)”. Campo de Agramante: Revista de Literatura 10, 23-46. Disponible en línea: http://www.cervantesvirtual.com/obra/travesia-pablo-garcia-baena/ [06/01/2021].

García Baena, P. (2018). Poesía completa, L. A. de Villena (ed.). Madrid: Visor.

García de la CONCHA, V. (1995). "Punto umbrío". ABC, 19 de mayo, 22.

García GalÁn, T. (2003). Esteticismo como rebeldía: la poética de Pablo García Baena. Sevilla: Renacimiento.

García Martín, J. L. (1996). Treinta años de poesía española (1965-1995). Sevilla / Granada: Renacimiento / Comares.

(1997). "Devocionario". ABC, 26 de diciembre, 19.

GRACIA GARCÍA, J. y RUIz CARNICER, M. Á. (2001), La España de Franco (1939-1975). Cultura y vida cotidiana. Madrid: Síntesis.

GiménEZ-Frontín, J. L. (1987). “La iconografía erótica de Ana Rossetti”. La Vanguardia, 19 de febrero, 41.

GonzÁlez Iglesias, J. A. (2010). "El universo clásico en Pablo García Baena”. En Pablo García Baena: misterio y precisión. Actas del Congreso internacional celebrado en Córdoba del 18 al 20 de noviembre de 2009, C. Fernández Prieto (ed.), 88112. Sevilla: Renacimiento.

Lafollette Miller, M. (1995). "The Fall from Eden: Desire and Death in the Poetry of Ana Rossetti”. Revista de Estudios Hispánicos 29.2, 259-277.

Llorente Torres, M. (2000). "El eros subversivo de la poesía de Ana Rossetti”. En Palabra y deseo. Espacios transgresores en la Poesía Española, 1975-1990, M. Llorente Torres (ed.), 103-126. Málaga: Universidad de Málaga.

LujÁn Martínez, E. R. (1997). "Los devaneos de Erato: el mundo clásico de Ana Rossetti”. Epos: Revista de Filología 13, 77-88. Disponible en línea: http://revistas.uned.es/index.php/EPOS/article/download/10010/9550 [06/01/2021]. 
Mangini, S. (1996). "Las vanguardias y el discurso del deseo". En Breve historia feminista de la literatura española (en lengua castellana), vol. 3 La mujer en la literatura española: modos de representación desde el siglo XVIII a la actualidad, I. Zavala (ed.), 177-212. Barcelona / San Juan de Puerto Rico: Anthropos / Universidad de Puerto Rico.

Martínez Ruiz, F. (1987). "Devocionario. Ana Rossetti. III premio Rey Juan Carlos de Poesía”. ABC Literario, 28 de marzo, 48.

MERINO MADRID, A. (2015). La mitología clásica como instrumento para la construcción de una nueva identidad de género en la poesía española del siglo XX escrita por mujeres. Tesis doctoral dirigida por J. A. López Férez y R. Pedrero Sancho: UNED. Disponible en línea: http://e-spacio.uned.es/fez/view/tesisuned:FilologiaAmerino [06/01/2021].

PATRÓn SÁnCHEZ, M. (2018). “Ana Rossetti: 'Cada libro tiene su poética, cada libro tiene su universo, su sentido"”. Temblor. Asidero poético. Disponible en línea: https://temblorpoesia.com/ana-rossetti-libro-poetica-libro-universo-sentido [06/01/2021].

RobBins, J. (2004). “An Introduction, Postmodern by Design: Spectacle, Fashion, and Fashion Plates in Post-Franco Spain". En P/herversions: Critical Studies of Ana Rossetti, J. Robbins (ed.), 31-62. Lewisburg: Bucknell University Press.

Rosal, M. (2007). Carnavalización y poesía (Subversión erótica de símbolos religiosos en la poesía de Ana Rossetti). Córdoba: La manzana poética.

Rosas, Y. (2012), “Eros en la poesía de Ana Rossetti”, Revista Carácter 1.1, 143-158. Disponible en línea: http://www.upacifico.edu.ec/ojs/index.php/caracter/ article/download/7/7 [06/01/2021].

Rossetti, A. (2004). La Ordenación (Retrospectiva 1980-2004). P. M. Viejo (ed.). Sevilla: Fundación José Manuel Lara.

SÁNCHEZ DueÑAs, B. (2001). "Transgresión de mitos clásicos en la obra poética de Ana Rossetti”. En Romper el espejo. La mujer y la transgresión de códigos en la literatura española: Escritura. Lectura. Textos (1001-2000), M. J. Porro Herrera (ed.), 301-313. Córdoba: Universidad de Córdoba.

SHERnO, S. (1995). “Ana Rossetti o el jardín del deseo erótico". En Del franquismo a la posmodernidad. Cultura española 1975-1990, J. B. Monleón (ed.), 295-313. Madrid: Akal.

Ugalde, S. K. (1990). "Erotismo y revisionismo en la poesía de Ana Rossetti". Siglo XX/20th Century 7, 24-29.

(ed.) (1991). Conversaciones y poemas. La nueva poesía femenina española en castellano. Madrid: Siglo XXI Editores.

VIEJO, P. M. (2004). “Introducción”. En La Ordenación (Retrospectiva 1980-2004), P. M. Viejo (ed.). 7-24. Sevilla: Fundación José Manuel Lara.

VILAs, M. (1995). "Pablo García Baena, et in Arcadia ego". Poesía en el campus 32, 411. 
Villena, L. A. DE (2010). "Los mitos de la infancia y la adolescencia en Pablo García Baena”. En Pablo García Baena: misterio y precisión. Actas del Congreso internacional celebrado en Córdoba del 18 al 20 de noviembre de 2009, C. Fernández Prieto (ed.), 141-156. Sevilla: Renacimiento.

(2018). "Introducción a la poesía de Pablo García Baena”. En Pablo García Baena. Poesía completa, L. A. de Villena (ed.), 7-35. Madrid: Visor.

VILlENA, L. A. DE, ED. (2007). El fervor y la melancolía: los poetas de “Cántico” y su trayectoria. Sevilla: Fundación José Manuel Lara.

Wilcox, J. C. (1989). "Observaciones sobre el Devocionario de Ana Rossetti”. La Chispa '89: Selected Proceedings, 335-344.

ZALDÍVAR, M. I. (1998). La mirada erótica en algunos poemas de Ana Rossetti y Gonzalo Millán. Santiago de Chile / Barcelona: RIL / Café Central.

Fecha de recepción: 15/01/2021

Fecha de aceptación: 01/07/2021 